\title{
Efeitos da reestruturação produtiva mundial sobre as atuais dinâmicas socioeconômicas de desenvolvimento local dos territórios
}

Jorge Luiz Amaral de Moraes ${ }^{1}$ - Sérgio Schneider ${ }^{2}$

\section{Resumo}

Este texto apresenta alguns resultados de uma revisão sobre a atual reestruturação produtiva mundial e os seus efeitos sobre as novas dinâmicas socioeconômicas de desenvolvimento regional. Os estudos sobre o tema têm sido polarizados por duas visões: a da globalização como única saída e a do desenvolvimento local e/ou endógeno. 0 objetivo foi identificar o fio condutor que vai da crise do regime de acumulação fordista até as novas formas territoriais e institucionais locais de poder e de produção e, também, como se estabelecem as novas relações entre a regulação global e a governança das dinâmicas locais. Apresentam-se subsídios teórico-metodológicos regulacionistas e institucionalistas, para serem utilizados no estudo das atuais dinâmicas socioeconômicas e nas ações e políticas de desenvolvimento dos territórios. Esses subsídios foram articulados pelos mesmos pressupostos teóricos que sustentam os argumentos favoráveis à necessidade de "imersão" (embeddedness) do sistema de economia de mercado no sistema social. Argumenta-se por uma saída alternativa que representa uma perspectiva territorial e institucionalista, na qual os efeitos do capitalismo global sobre as dinâmicas locais de desenvolvimento são mediadas por estruturas de regulação e governação, que geram dinâmicas que podem aproveitar as oportunidades externas e as potencialidades locais dos territórios. Por isso, então, para promover o desenvolvimento de um território, é necessário estudar o grau e a forma de aproveitamento dos recursos e potencialidade endógenos e os elementos determinantes das diferentes dinâmicas estruturais e institucionais.

Palavras-chave: Reestruturação produtiva. Desenvolvimento territorial. Dinâmicas de desenvolvimento.

\footnotetext{
${ }^{1}$ Professor da Universidade de Santa Cruz do Sul - Unisc (RS) e Faculdades Integradas de Taquara - Faccat - Taquara (RS). Engenheiro Agrônomo, Mestre em Economia Rural, Doutor em Desenvolvimento Rural.

jmoraes@faccat.br

2 Professor do PPGDR da Universidade Federal do Rio Grande do Sul - UFRGS (RS). Sociólogo, Doutor em Sociologia.

schneider@ufrgs.br
} 


\section{Abstract}

This paper presents some results of a review about the current world productive reorganization and its relationship with the new socioeconomic dynamic of regional development. Studies on the theme have been polarized by two views, of the globalization as the only way out and the local and/or endogenous development. The goal was to identify the common thread that runs from the crisis of Fordist regime of accumulation to the new forms of territorial and institutional local power and production, and also how to establish new relationships between global regulation and governance of local dynamics. Are presented theoretical and methodological subsidies, regulationists and institutionalists, for use in the study the current socioeconomic dynamics and in the actions and policies of development of the territories. These subsidies were articulated by the same theoretical premises that support the arguments in favor the necessity of "embeddedness" of market economy system in the social system. It argues for an alternative exit that represents a territorial and institutionalist approach, in which the effects of global capitalism on local dynamics of development are mediated by regulatory and governance structures, that generate dynamics that can take advantage of external opportunities and local potential of territories. So then, to promote the development of a territory it is necessary to study the extent and form of use of the endogenous resources and potentiality and the determining elements of different structural and institutional dynamics.

Keywords: Economic restructuring. Territorial Development. Dynamics of development.

\section{Introdução}

A partir de um contexto de crise do capitalismo fordista, que teve início na década de 1970, despontam algumas interpretações sobre os rumos da atual reestruturação produtiva mundial e seus reflexos sobre as formas de desenvolvimento local. O debate sobre as direções da reestruturação produtiva mundial é polarizado pelas correntes de pensamento que defendem as ideias de globalização, por um lado, e a das visões locais e endógenas sem a presença de mercados formais, por outro.

Para os regulacionistas, no atual modelo de desenvolvimento fordista, acontece uma crise de eficácia e uma falta de legitimação do modelo, que resulta da falta de flexibilidade e de sustentabilidade das cadeias de produção e pela ineficiência da macroeconomia para garantir a continuidade da acumulação capitalista. Então, uma das estratégias de "saída" do fordismo seria a experimentação flexível do trabalho, para resolver a baixa "produtividade da coerção direta" e aprofundar as relações capitalistas, dando início a uma nova configuração internacional da divisão do trabalho. Com isso, emergem novos setores de acumulação e há transferências de empresas para regiões periféricas ou semiperiféricas, com níveis salariais mais baixos e crescente aumento do número de pequenas empresas, em que o "processo de trabalho é mais flexível e em que se efetuam economias máximas nos custos de produção" (BENKO, 2002, p. 32).

Outras vertentes teóricas que interpretam as mudanças do capitalismo contem- 
porâneo divergem da interpretação dos regulacionistas. Algumas em relação às causas da crise, como a dos "neoschumpeterianos", e outras com relação aos desdobramentos atuais e futuros desse processo de mudança, essas ficando mais próximos de um "neofordismo", o que seria apenas uma adaptação do capitalismo a uma nova situação, uma nova etapa do capitalismo, denominada de "globalização". Para esses, entre os quais se incluem os defensores de um neoliberalismo, nas sucessivas etapas do desenvolvimento capitalista - um encadeamento de relações sociais que se refletem nas tecnologias e formas de produção predominantes - a globalização é apenas mais uma etapa que está sendo percorrida neste início de século. Mas todas essas interpretações, assim como a dos regulacionistas, afirmam que a capacidade dos Estados-nação de controlar as atividades econômicas e de serem identificados com suas empresas (nacionais) tem diminuído significativamente.

$\mathrm{Na}$ esteira desse debate em torno dos caminhos da reestruturação produtiva capitalista e das mudanças no modo de regulação capitalista, desde o início da década de 1970, intensificaram-se os estudos por meio das abordagens "locais", "endógenas" e, mais recentemente, "territoriais" do desenvolvimento (BENKO, 2002; BENKO; LIPIETZ, 1994; REIS, 1992; 2006; VÁZQUEZ-BARQUERO, 2001). Assim, diversos estudos passaram a dar mais ênfase aos fatores endógenos, à ação dos atores sociais locais, ao papel das instituições e à dimensão territorial nos processos de desenvolvimento (REIS, 1998; 2006). Por isso, a questão a ser respondida neste artigo é sobre o fio condutor teórico que vai da crise do regime de acumulação fordista até as novas formas territoriais e institucionais locais de poder e de produção e como se estabelecem as novas relações entre a regulação global e a governança das dinâmicas locais. Como resposta, apresentam-se alguns referenciais teórico-metodológicos da "Teoria da Regulação" e do "Institucionalismo" com potencial para serem utilizados no estudo das atuais dinâmicas de desenvolvimento socioeconômico dos territórios, articulados com as perspectivas territoriais e institucionais do desenvolvimento. Nessas articulações entre esses referenciais e a escolha das variáveis de identificação das relações entre o global e o local, dentro do território, também foram utilizados os pressupostos teóricos que sustentam a "imersão" ou "enraizamento" (embeddedness) da economia de mercado no sistema social, com base em Polanyi (2000).

Neste artigo, apresenta-se, também, a alternativa territorial, que poderá representar uma situação onde os efeitos do capitalismo global sobre as dinâmicas locais de desenvolvimento possam ser mediadas pelas suas estruturas internas de poder, a regulação e a governação. Essas mediações geram diversificadas dinâmicas socioeconômicas de desenvolvimento, que podem aproveitar ou desperdiçar as diferentes potencialidades locais dos territórios e, ao mesmo tempo, as oportunidades externas.

Esses são os subsídios teóricos de sustentação da abordagem para a interpretação de um modelo de desenvolvimento socioeconômico dos territórios, que poderão ser úteis para ações e políticas públicas que tenham como objetivo a redução da pobreza e a inclusão social, visando ao desenvolvimento territorial sustentável. Mas é necessário também conhecer as diferentes dinâmicas territoriais de desenvolvimento e abrir a possibilidade de participação democrática para todos os atores. Por isso, alguns pontos dessa abordagem - como capitalismo flexível, a perspectiva territorial de desenvolvi- 
mento e as dinâmicas socioeconômicas dos territórios - serão desenvolvidos a seguir com mais detalhes.

\section{Da crise do regime de acumulação fordista ao capitalismo flexível}

A literatura sobre as novas configurações do capitalismo contemporâneo vem destacando as dimensões global e local como os dois lados de uma mesma moeda, como resultado da crescente importância da ação dos atores e do espaço na economia. Por um lado, a globalização está relacionada com a expansão da escala de atuação das empresas, ampliando os mercados e a organização da produção. Por outro lado, o local passa a ser o espaço onde as potencialidades e os recursos são aproveitados, em conjunto com as oportunidades externas, dentro de uma estratégia dos atores locais, que inclui a organização do território e políticas de desenvolvimento local. As situações temáticas abordadas neste estudo representam uma tentativa de captar essas duas situações dentro de um território, enfatizando, além das determinantes globais, os fatores endógenos, a ação dos atores sociais locais, as estruturas institucionais e a dimensão territorial nos processos de desenvolvimento.

A abordagem regulacionista sustenta que a evolução do sistema capitalista de produção acontece por meio de modelos de desenvolvimento baseados em regimes de acumulação e modos de regulação muito específicos. Portanto, o regime de acumulação e o modo de regulação são os dois lados da mesma moeda de um modelo de desenvolvimento que se baseia no modo de produção capitalista, com fases estáveis de acumulação de capital ou modelos de desenvolvimento com regularidades que garantem a reprodução do sistema. O regime de acumulação e o modo de regulação são interrompidos por crises ou períodos de recessão que servem de ponte entre os períodos de estabilidade de dois modelos sucessivos.

As estratégias de reestruturação das forças capitalistas para tentar contornar as contradições do atual regime de acumulação passam pela "luta contra a rigidez", as quais, segundo Benko (2002), definem um novo campo de disputas sociopolíticas entre a "regulação keynesiana da economia liberal" e a "regulação liberal da economia keynesiana". Essas mudanças devem ser interpretadas como resultado da emergência de um sistema denominado de pós-fordismo, que permite que as grandes empresas tenham maior mobilidade e obtenham vantagens sobre a qualidade de novos instrumentos socioeconômicos mais flexíveis. Dessa forma, o consumo local e os mercados de trabalho se tornam recursos que podem ser incluídos ou excluídos dos circuitos globais de acordo com as necessidades dessas corporações, enquanto que o local é visto como potencializador ou desestimulador das estratégias das corporações transnacionais. Assim, caminhamos para uma nova configuração capitalista, denominada por Benko (2002) de acumulação flexível, que inclui práticas e estratégias de produção e regulação pós-fordista, com um mix de formas de organização da produção neofordistas com formas de fordismo periférico.

Considerando que estamos em um período transitório de desenvolvimento, entre o declínio do regime de acumulação fordista e o aparecimento de um novo modelo de 
acumulação, as mudanças geográficas dos espaços de produção coincidem com outras mudanças da organização da produção, provocadas pelas exigências de um novo regime de acumulação. Essas requerem flexibilidade nos processos de produção, no desenvolvimento de produtos e na (des)regulação das relações de trabalho. Benko (2002) tem a convicção de que as novas técnicas de produção flexíveis e novos produtos provocaram uma reorganização do processo de produção global

Para Held e McGrew (2001), o aumento da regionalização da atividade econômica não provocou a divisão do mundo em blocos rivais, mas, ao contrário, "o regionalismo tem facilitado e incentivado muito a globalização econômica" (p. 43), porque proporciona um engajamento estratégico das economias nacionais e regionais nos mercados globais. Embora os principais fluxos econômicos globais ainda se concentrem em torno de três grandes centros de poder econômico (Estados Unidos, Europa e Japão), o predomínio dessas economias vem sendo diluído, na medida em que a "globalização econômica vai alterando significativamente a geografia da atividade e do poder econômico mundial" (HELD; MCGREW, 2001, p. 32).

\section{A alternativa da globalização}

David Held e Anthony McGrew, em seu livro Prós e Contras da Globalização (2001), procuram identificar os argumentos que estruturam as duas principais visões interpretativas que, segundo eles, caracterizam, por um lado os "globalistas", que acham que a globalização veio para ficar e, por outro os "céticos", que não acreditam na tese de uma economia, sociedade, política, cultura ou ambiente "globalizados". Segundo eles, a origem da ideia da globalização, embora não com esse nome, está nos "anos dourados" do liberalismo, entre o final do século XIX e o início do século XX. No entanto, o uso do termo "globalização" se popularizou somente a partir dos anos 1970.

Por falta de uma alternativa melhor para o mundo, "a ideia da globalização adquiriu a aura de um novo paradigma" (HELD; MCGREW, 2001, p. 23). Hoje, tal como o da modernização na década de 1960, o discurso da globalização parece convincente com relação à condição humana contemporânea. A globalização passou a predominar entre os estudos das ciências sociais, mas gerando uma busca por abordagens que analisassem, ao mesmo tempo, as questões internas e as externas, as nacionais e as internacionais ou as relações locais e globais, como uma via de mão dupla.

Para Held e McGrew (2001), o conceito de globalização se consolida a partir da ampliação dos fluxos globais e das relações e atividades sociais por meio das regiões e fronteiras, que levam a uma maior interdependência dos Estados e das sociedades ligados aos sistemas mundiais e às redes de interação. Para esses autores, as definições de globalização destacam a ação de atores sociais distantes, mudança na interpretação das relações espaço-temporais, crescimento da interdependência entre as economias e sociedades nacionais, surgimento de um mundo sem barreiras para as atividades socioeconômicas e mudanças nas relações de poder e nas articulações inter-regionais.

Entretanto, conforme Fiori (1994), embora ainda sobreviva a ideia de nação, os atuais processos sociais, econômicos, políticos e culturais vêm promovendo a globaliza- 
cão. As estruturas e os pensamentos baseados no nacional vêm sendo enfraquecidos ou recriados com outros significados devido à dinâmica das relações, dos processos e das estruturas em escala mundial, colocando um novo desafio para as ciências sociais. Com a globalização, as nações transformaram-se em espaços, territórios ou pontes entre o local e a sociedade global.

Embora considerando a dificuldade para se medir a evolução do sistema produtivo capitalista, Benko (2002) afirma que mudaram muito as bases do processo de desenvolvimento socioeconômico regional nos últimos cem anos. Nos anos 1980, teve início uma nova etapa desse processo, cuja dinâmica é uma transição entre dois regimes de acumulação e seus modos de regulação, na qual a tecnologia é essencial e as indústrias "de ponta" e os serviços especializados se destacam. A emergência e a consolidação de um novo regime de acumulação e suas dinâmicas devem ser analisadas como uma mudança qualitativa da organização das forças produtivas em resposta ao aprofundamento da crise do regime de acumulação fordista. Nos últimos vinte anos, observam-se sinais de um novo período de desenvolvimento do capitalismo mundial (neofordista ou pós-fordista), fundado na flexibilidade socioeconômica crescente, o qual vem sendo chamado de regime de acumulação flexível por diversos autores (BENKO, 2002).

\section{A hipótese do capitalismo flexível}

Sob o ponto de vista das teorias dos ciclos econômicos longos, duas das mais importantes correntes teóricas de interpretação do mundo contemporâneo, os neoschumpeterianos e os regulacionistas, cada um a seu modo, afirmam que estamos vivendo um momento de inflexão entre duas fases do capitalismo. Segundo elas, estamos iniciando um novo ciclo ou regime de acumulação capitalista, passando do fordismo para um pós-fordismo.

Para os neoschumpeterianos, o crescimento do pós-guerra ocorreu em consequência, por um lado, da intervenção do Estado, que, sob a influência dos princípios keynesianos, sustentou algumas atividades econômicas e, por outro, da liberação das trocas internacionais, que facilitou a expansão e a difusão da inovação. Isso gerou uma regulação geral e maiores possibilidades de crescimento tecnológico. Porém esse crescimento vigoroso foi interrompido na década de 1970, quando os investimentos em inovação e no progresso técnico atingiram a sua fase de maturação. As causas exógenas, como o aumento do preço do petróleo e de outras matérias-primas, agravaram a situação e precipitaram a necessária adaptação estrutural. Apesar de seu potencial explicativo, essa linha de pensamento foi alvo de críticas, principalmente por tratar como exógenas algumas variáveis que seriam endógenas, e alguns autores formularam outras teses para compreender e explicar a evolução do contexto econômico e social.

Para os autores regulacionistas (BENKO; LIPIETZ, 1994; BENKO, 2002; BOYER, 1994; 2004; BOYER; SAILLARD, 1995), a estabilidade temporária do sistema capitalista é obtida por meio da criação de regimes de acumulação, períodos históricos com condições favoráveis à reprodução do processo de acumulação de capital e à manutenção de níveis aceitáveis da ordem socioeconômica capitalista. Não é, necessariamente, um pro- 
cesso estável e único com um mesmo modo de produção no longo prazo, pois sempre há a possibilidade de ocorrerem rupturas, conflitos e crises. Os mecanismos reguladores ou o conjunto de normas, instituições e relações de poder que dão suporte ao regime de acumulação denominam-se modo de regulação. Essas são as formas institucionais, as redes ou as normas explícitas ou implícitas que asseguram a compatibilidade dos comportamentos dentro de um regime de acumulação, considerando as relações sociais e os seus conflitos (LIPIETZ, 1991). A evolução de um regime de acumulação acontece a partir de formas de regulação, os procedimentos sociais que garantem as modificações das normas de produção e consumo do regime de acumulação e de formas institucionais, que concretizam ou operacionalizam as formas de regulação (LIPIETZ, 1991). É possível afirmar que essas formas de regulação induzem os agentes econômicos a se relacionarem por meio das formas institucionais. Essas são codificações das relações sociais fundamentais, que estão em constante evolução e permitem uma melhor compreensão das regularidades de um determinado período histórico ou das dinâmicas de desenvolvimento de um território (BOYER, 1994). Para os regulacionistas, as estratégias de superação dos problemas ligados à crise do fordismo e do capitalismo e nas relações de trabalho direcionam o foco dos capitalistas para a experimentação flexível do trabalho.

Então, referindo-se frequentemente ao caso da "Terceira Itália", os autores regulacionistas afirmam que, com a crise do regime de acumulação fordista, emergiu um novo regime de acumulação, um sistema produtivo mais flexível e um novo sistema ou modo de regulação das relações capital-trabalho, a industrialização difusa. Essa pressupõe processos flexíveis de trabalho e a produção descentralizada para várias pequenas unidades. Mas é necessária uma dispersão de unidades industriais de pequeno porte em pequenas e médias cidades e com uma organização sindical mais fraca do que a dos grandes centros urbanos, o que possibilita a contratação de trabalho com salários menores e formas mais flexíveis de trabalho, como atualmente vem acontecendo no Brasil. Essa forma de organização da produção industrial poderá ter um grande potencial no contexto de globalização, pois a sua flexibilidade favorece a segmentação de operações produtivas em locais que ofereçam condições mais favoráveis.

A especialização flexível e a industrialização difusa resultam da crise do capitalismo fordista e, ao mesmo tempo, surgem como soluções desejáveis para as crises socioeconômicas do sistema. A primeira, porque combina a emergência de novas tecnologias com o aumento da qualidade da produção a partir das estratégias empresariais, fazendo surgir a noção de industrialização difusa. Essa se diferencia da industrialização fordista porque não depende diretamente da concentração urbana das indústrias, de um exército industrial de reserva - obtido à custa de um acelerado processo de migração - e de grandes unidades produtivas.

Por fim, quando se refere ao tema do desenvolvimento, Reis (1992) afirma que, com o esgotamento dos modelos centralizados de desenvolvimento, o local reaparece como solução para duas problemáticas relativamente diferentes. Uma analisa os sistemas produtivos locais (SPLS) e estuda o funcionamento das economias locais e a própria concepção de território, na qual esse deixa de ser apenas receptor de indústrias e passa a ser um agente de industrialização. A outra analisa o desenvolvimento local e estuda as relações entre os governos e a sociedade local para a solução de problemas sociais e de 
carências de recursos locais, em que os atores locais passam a empreender ações para fazer crescer a economia local e reestruturar seus sistemas produtivos.

A seguir, procura-se demonstrar a contribuição das perspectivas territoriais do desenvolvimento para o estudo das dinâmicas socioeconômicas de desenvolvimento dos territórios.

\section{A abordagem territorial do desenvolvimento}

A partir da década de 1970, o espaço passou a ter um novo papel sócio-político, cresceu a importância da instância política e verificou-se que o aparelho governamental não era mais o único instrumento de poder. Então, o Estado aparece como aparelho político global e não apenas como governo. Assim, o espaço reassume sua força e recupera-se a noção de território. Dessa forma, na definição de território incorporam-se as relações multidimensionais de poder e o espaço em vez de produto reflexo da sociedade passa a ser o local onde acontece a reprodução social. O espaço é o principal constituinte da realidade social e a dimensão material concreta das relações sociais (BECKER, 1986).

As novas abordagens da geografia econômica e da sociologia econômica, em termos de definição do território, têm uma perspectiva muito dinâmica, o que parece relevante, já que os sistemas estão em constante evolução, embora em graus e tempos bastante diferenciados. O território é resultante da relação da sociedade com o espaço, quando neste se incorpora a sociedade com suas relações econômicas e de produção. Para que se tenha um território, é necessário que a sociedade ou grupos sociais se apropriem do espaço físico, ampliem e utilizem as inovações tecnológicas e que exista um sentimento de pertencimento ou a identificação da sociedade com o seu território.

A dinâmica territorial e institucional associa o território aos atributos da diferenciação e da aglomeração (ou densidades), as quais, de acordo com Reis (2006), justificam a existência do território. Essa dinâmica está relacionada com lógicas de proximidade, as quais dão origem às aglomerações, que servem de base para as estruturas institucionais. Além disso, o desenvolvimento territorial depende da capacidade de cada território para mesclar e aproveitar, ao mesmo tempo, as suas potencialidades locais e as oportunidades externas. Para que o território possa ser utilizado como recurso do desenvolvimento, o autor afirma que é necessária a identificação das aglomerações "locacionais" a fim de que se possa conhecer o território e aproveitar as suas potencialidades.

De acordo com Schneider e Tartaruga (2005), para se utilizar o território na perspectiva do desenvolvimento, é necessário estabelecer a diferença entre o seu significado conceitual ou analítico e o seu significado instrumental ou prático. Desse modo, a abordagem territorial do desenvolvimento pressupõe, ao mesmo tempo, a ação sobre o espaço e a mudança das relações sociais nele existentes, portanto com objetivos instrumentais e práticos. Os autores argumentam que há duas razões para se compreender por que as abordagens territoriais tornaram-se uma referência para a interpretação de processos e uma ferramenta para a intervenção, estimulando o interesse pelos enfoques e abordagens territoriais. A primeira está relacionada ao atual contexto de crise do fordismo e do processo de reestruturação do capitalismo contemporâneo, que teria 
desenvolvido, em resposta a essa crise, um novo regime de acumulação denominado de "acumulação flexível". A segunda razão do interesse pela abordagem territorial relaciona-a com os aspectos políticos e institucionais derivados da crise do Estado e da redução do seu poder de regulação. Essa crise do Estado está relacionada à sua incapacidade crescente de regulação e interferência na economia privada, decorrente principalmente do atual processo de globalização dos fluxos financeiros e produtivos e da economia de mercado.

Por esse motivo, nos próximos itens, procura-se fazer uma exposição dos conceitos analíticos de território e, posteriormente, dos seus significados instrumentais e práticos que lhe são atribuídos pelos enfoques ou abordagens territoriais.

\section{O território como referência para ações e políticas de desenvolvimento}

Neste item, buscam-se argumentos epistemológicos que sustentam os atuais conceitos de território, as relações de poder na formação dos territórios e a sua diferenciação com relação à noção de espaço. Também se analisa a sua adequação às mais recentes utilizações nas abordagens territoriais do desenvolvimento e a possibilidade de a abordagem territorial do desenvolvimento tornar-se um instrumento para políticas públicas.

Segundo Becker (1986), é a partir de Ratzel, em 1897, que têm início os estudos dentro da geografia política, quando o território passa a ser a expressão concreta das unidades políticas no espaço. Para relacionar a nova geopolítica com as relações de poder multidimensionais em diferentes níveis espaciais, a autora afirma que o espaço não é mais apenas produto reflexo da sociedade, mas a dimensão material concreta das relações sociais, constituinte da realidade social e sinônimo de poder. A autora argumenta que, enquanto na corrente funcionalista neoclássica o espaço é visto como uma estrutura autônoma do processo de produção e da sociedade, na corrente marxista o espaço é visto como reflexo das relações sociais de produção. Na primeira, o espaço é produtor, o conflito entre unidades espaciais substitui o conflito de classes e o Estado cria e concilia o conflito de interesses entre o centro e a periferia. Na segunda, o espaço é produzido e a teoria e a prática do desenvolvimento regional, segundo seus seguidores, não servem para solucionar os conflitos gerados internamente.

Atualmente, enquanto se define espaço apenas como um campo de existência, o qual não desaparece quando é criado o território, este tem sua forma ou limites e sua malha territorial determinadas pelas manifestações das relações de poder, que têm como origem a população, o território e os recursos (RAFFESTIN, 1993). A população está na origem do poder porque é de onde vem o potencial de transformação, ou seja, é o elemento dinâmico de onde se origina a ação. Enquanto o espaço serve de cenário, o território é a cena do poder e o lugar onde acontecem todas as relações, contudo, sem a população, esse é apenas potencialidade. Como o território é um produto gerado pela prática social e consumido como meio, os recursos determinam os horizontes possíveis, o alcance da ação e o processo de produção do território.

O uso do conceito de território pode ser um importante instrumento para estabe- 
lecer os limites das vantagens potenciais resultantes do desenvolvimento desse território, tanto físicos como simbólicos. No final do século $X X$, em vários países, as perspectivas territorialistas começaram a ter destaque na economia em função da importância da variável espaço na busca de equidade socioeconômica e na avaliação do papel dos territórios na formação das estruturas e das dinâmicas sociais contemporâneas (MORAES, 2008).

Além do interesse da academia pelos conceitos relacionados ao tema do território e do desenvolvimento territorial, verifica-se também que esse assunto vem despertando o interesse dos governos e das agências e organizações nacionais e internacionais de desenvolvimento. O território passa a ser interpretado como uma unidade de referência e mediação para as ações e políticas públicas de desenvolvimento territorial. Essas considerações são de grande relevância quando se trata de regiões e países periféricos, como no caso da América Latina, onde se verifica que as diversidades históricas, socioeconômicas e culturais dos territórios são significativas.

No entanto, para que seja constituído um território, é necessário que a sociedade ou grupos sociais se apropriem do espaço físico, ampliem e utilizem as inovações tecnológicas e exista um sentimento de pertencimento ou de identificação da sociedade com o seu território. A sua legitimação passa pelo discurso e pela negociação em relação à história, à política, à ciência, ao mercado e às relações sociais. A territorialidade está relacionada com a presença de condições ou situações que indiquem a existência de um território.

Desde o início dos anos 1980, os atores locais e regionais passaram a realizar ações no sentido de incrementar o crescimento da economia local e realizar a reestruturação de seus sistemas produtivos, fazendo surgir, então, as políticas de desenvolvimento local. A política econômica local, segundo Vázquez-Barquero (2001), seria uma abordagem "de baixo para cima" da política de desenvolvimento, com os atores locais desempenhando os papéis centrais. Dessa forma, as estratégias locais de desenvolvimento deveriam estimular o surgimento e a expansão de empresas locais e favorecer o aproveitamento de recursos que pudessem atrair empresas externas.

A legitimação do território passa pelo discurso e pela negociação interna e entre - local e o global, em relação à história, política, ciência, sociedade e ao mercado. O local passa a ser um espaço de cooperação e conflito, um novo referencial da coesão social, antes estabelecida somente pela regulação e que agora substitui grande parte do papel regulador das estruturas e instituições do Estado-nação, as quais perdem parte de seu poder para outros atores sociais. Com isso, o Estado-nação não é mais capaz de realizar sozinho a coesão social, e, então, os atores locais passam a administrar parte dos meios de vida dos cidadãos, crescendo a importância da governação do território. Esse tema referente ao território como o lugar de encontro e de disputa entre a regulação global e a capacidade local de governação, entre o determinismo global e o desenvolvimento local, será abordado a seguir.

Território: lugar de encontro entre global e local

Reis (2006) afirma que a relação entre o global e o local, os quais o autor chama 
de "mobilidades" e "territorializações", é uma tensão, o que se assemelha muito com a ideia de "duplo movimento" de Polanyi (2000), e gera processos de transformações globais nos sistemas. Para Reis (2006), a ideia de reprodução de determinantes da globalização não é útil para configurar uma noção de território, porque a origem dos territórios não é apenas uma questão de diferenciação de escalas do Estado, do mercado, do capitalismo ou da globalização. Para compreender as relações de poder e a estruturação político-econômica do desenvolvimento, ele sugere a utilização das ideias de "morfologia do poder" e a noção de "polimorfismo" das sociedades contemporâneas no lugar do desenvolvimento funcionalista e propõe uma alternativa institucionalista.

A evolução das relações nas sociedades contemporâneas favorece os conceitos e definições que enfatizam a relação dialética entre o local e o global. As relações sociais locais são consequências também das ações dos atores globais, com estas ações se concretizando no âmbito local. Ou seja, o global não existe sem o local, e esse se caracteriza pelas relações sociais estruturadas pelas relações sociais globais. Como há necessidade de se buscar um equilíbrio entre global e local, o foco não deve ser apenas no local, mas também nas relações e interações entre os diferentes territórios e com o exterior, nesse caso, o local reage e responde aos estímulos provocados pelas ações dos atores globais (MORAES, 2008).

O território é o ponto de encontro entre as formas de mercado, os modos de regulação social e os atores do desenvolvimento. Sob o ponto de vista empresarial, o território tem um papel importante nas novas atividades e tecnologias e é o lugar onde se organizam as formas de cooperação entre empresas e onde se decide a divisão social do trabalho. Nos estudos sobre desenvolvimento territorial, é importante a interpretação do território como um ambiente local que sofre influência de variáveis internas (participação dos atores locais, causas e efeitos ambientais, socioambientais e culturais) e interage com os sistemas territoriais de maior escala ou globais. Visto dessa forma, o território é a arena de disputa ou de competição entre o local e o global, onde a regulação e a governação são realizadas pelos atores e instituições que têm o poder de dominação sobre o mesmo. Por um lado, no local, tem destaque a importância dada à sociedade, à natureza, à reciprocidade e à economia "solidária"; por outro, no global, o que é determinante é a economia de mercado.

Quando se refere à natureza das estruturas e das dinâmicas da sociedade e da economia, Reis (2006) afirma que essa questão tornou-se relevante quando a "metáfora territorial da globalização" passou a dominar o discurso corrente. Essa se apoia nas escalas territoriais relevantes para entender o funcionamento socioeconômico, mas as relações entre o espaço e os atores são hierárquicas, previsíveis e implicam que as relações locais são apenas derivações das relações globais. Sendo a globalização totalizante, o local interessa apenas como um "canal de reprodução" do global e, por essa razão, as possibilidades de expressão territorial se limitam às alternativas de submissão, resistência ou exclusão. Com relação a esse assunto, Reis (2006) levanta duas questões que merecem uma reflexão: a racionalidade e a ação dos atores e as suas relações com o espaço onde ocorre o "processo da vida" são funcionalmente determinados pelas dinâmicas externas do capitalismo, do mercado ou da globalização? Ou, ao contrário, há outros mecanismos de coordenação que dão poderes e ferramentas aos atores sociais 
para que eles possam perseguir os seus objetivos e concretizar os seus propósitos? 0 autor responde positivamente à segunda questão e argumenta que esses mecanismos de coordenação são fundamentos que estão presentes na construção de um conceito de território que responde à questão do seu papel nas dinâmicas sociais.

Reis (2006) destaca a contribuição da perspectiva territorial como uma nova ferramenta de conhecimento, para o estudo das dinâmicas socioeconômicas, das formas de estruturação das sociedades e, ao mesmo tempo, do significado do território para os processos e fenômenos sociais. Para o autor, os territórios são construções sociais, discursivas e materiais, que assumem materialidades, conhecimentos e relações que têm "espessura" e duração e não sofrem transformações "instantâneas e permanentes". O território é uma matriz relacional, formada pelas interações que "estruturam o mundo", do qual o território também faz parte.

Segundo Reis (2006), o mundo é representado por uma visão em que há espaços estruturais de iniciativa e de autonomia, onde a incerteza e as "trajetórias inesperadas" fazem parte. As dimensões proximidade e densidade formam a rede matricial interna dos territórios, que representam a identidade, a capacidade dinâmica e o conflito. A dimensão polimorfismo estrutural representa a essência das relações de poder nos territórios e a forma como estes se inserem na estrutura mundial. O território é um recurso de desenvolvimento e um plano essencial da articulação e coordenação de políticas públicas. Ele tem um significado institucional relevante, pois é o lugar onde as pessoas vivem e interagem, onde as situações se concretizam (ou se materializam) e onde as instituições se fazem presentes (REIS, 2006).

A questão relacionada às diferentes dinâmicas dos territórios refere-se à compreensão da origem dos processos socioeconômicos, ou seja, por que esses processos se iniciam em um determinado local e não em outro ou qual é a "razão de ser" desses processos. Inicialmente, chega-se à pressuposição de que as relações resultantes do fator "proximidade" são determinantes na gênese das dinâmicas de desenvolvimento dos territórios. Para Pecqueur (2004), o território tornou-se a principal variável explicativa das dinâmicas econômicas, com a diversidade das condições históricas e culturais e das características socioeconômicas regionais, jogando um importante papel nas diferenças entre as trajetórias de desenvolvimento. Isso leva a outra questão, a da natureza das estruturas e das dinâmicas da sociedade e da economia, ou como são coordenados os processos coletivos e qual é o papel desempenhado pelos atores sociais e das relações entre os atores e os processos internos e externos.

A partir daí, é possível afirmar que o desenvolvimento dos territórios tem como "combustível" principal o uso efetivo das capacidades, das competências e das habilidades dos atores locais e da sua identidade social e histórica com o território. Isso pode ser realizado por meio do gerenciamento eficiente dos recursos atuais e potenciais, na incorporação de conhecimentos e na transformação de possibilidades externas em oportunidades internas, com o objetivo de resolver problemas ou atender necessidades locais, promoverem o dinamismo econômico e a melhoria da qualidade de vida da população. Ele pode ser visto como um novo paradigma de desenvolvimento, emergindo da organização de uma sociedade local em torno de uma estratégia de desenvolvimento. Por essas razões e características, a definição de desenvolvimento territorial tem sido 
confundida e utilizada como sinônimo desenvolvimento local, endógeno ou regional.

$O$ desenvolvimento territorial pode ser considerado um modelo com características endógenas porque se baseia na capacidade das comunidades locais para desenvolverem estratégias de desenvolvimento e a prática da solidariedade e da participação. Além desta, o desenvolvimento territorial pode ter origem endógena quando as comunidades se mobilizarem em torno de programas e processos permanentes de organização de capacidades, competências e habilidades endógenas. Assim, surge a noção alternativa e a abordagem do desenvolvimento territorial, quando essa se torna um modo de ação que valoriza os atributos políticos e culturais das comunidades e dos atores sociais. A capacidade de organização social, o grau de participação dos atores locais ou a coordenação de interesses dentro do território passa a ser pensada a partir de conceitos ligados ao institucionalismo e à noção de capital social. Enquanto esse se refere às características da organização social, como confiança, normas e sistemas, que contribuam apara aumentar a eficiência da sociedade, facilitando as ações coordenadas, o institucionalismo abrange todas as instituições, organizações, convenções, cultura, hábitos, costumes e regras. Becker (1986) também tem opinião semelhante quando argumenta que 0 potencial competitivo de qualquer território é resultado direto do seu capital social, da ação de suas instituições, do dinamismo de suas organizações e da participação social pró-desenvolvimento. Ou seja, são as dinâmicas diferenciadas de cooperação entre os agentes econômicos e os atores sociopolíticos locais que determinam as diversificadas dinâmicas dos processos de desenvolvimento territorial. Com isso, o território passa a ser interpretado como uma nova unidade de referência e mediação das ações do Estado.

A abordagem territorial vem sendo considerada como um novo paradigma de desenvolvimento, que emerge do processo de globalização e da organização das comunidades locais em torno de uma estratégia de ação, com identidade própria e fortalecendo a sua capacidade organizacional. 0 ponto de encontro entre esse duplo movimento de disputa entre global e local é no território, por meio das suas instituições. O potencial de competição e desenvolvimento dos territórios é resultado de suas dinâmicas socioeconômicas e institucionais. Ou seja, resultam das diferentes dinâmicas de cooperação entre os agentes econômicos e os atores sociopolíticos locais, consequentemente, das diferentes dinâmicas socioeconômicas de desenvolvimento territorial (MORAES, 2008).

Na próxima seção, apresentam-se algumas contribuições da Sociologia Econômica para a análise das atuais dinâmicas de desenvolvimento dos territórios e os seus principais elementos constituintes. Para isso, recorre-se às teses de Karl Polanyi a fim de se estabelecerem as prováveis ligações das dinâmicas socioeconômicas dos territórios com as visões globais da "Teoria da Regulação" e do "Institucionalismo".

\section{Dinâmicas socioeconômicas de desenvolvimento dos territórios}

O objetivo principal desta seção é demonstrar a importância do debate em torno da vinculação entre a dimensão territorial e institucional do desenvolvimento, a origem social dos mercados e as formas específicas de interação social a partir de algumas conclusões teóricas de Polanyi (2000). Com isso, esperam-se estabelecer algumas possíveis 
pontes ligando a Teoria da Regulação e o Institucionalismo à abordagem teórico-metodológica e multidisciplinar do Desenvolvimento Territorial. Esses representam a visão territorial do desenvolvimento e uma visão global do sistema econômico e estudam as variáveis globais, potencialmente, determinantes das dinâmicas locais de desenvolvimento dos territórios.

Na década de 1990, a principal questão dos modelos e abordagens de desenvolvimento territorial era o conhecimento das causas da variação dos níveis de desenvolvimento econômico dos diversos territórios, quando esses tinham disponíveis as mesmas condições de acesso aos recursos e fatores produtivos. No debate atual sobre desenvolvimento territorial, sempre se destaca a importância dada às atividades econômicas locais e o papel dos diversos atores sociais e instituições, incluindo as formas de governos locais, as redes sociais e os diversos tipos de agentes econômicos. Além disso, quando a preocupação é com as políticas e projetos de desenvolvimento regional, emergem novas abordagens de interpretação que consideram as especificidades do território e o seu valor estratégico para os atores sociais.

Então, o conceito de desenvolvimento territorial pode ser resumido como um processo histórico de transformação social, quando os atores sociais utilizam suas capacidades pessoais e institucionais para mobilizar os seus recursos territoriais para produzir, distribuir e consumir de forma sustentável e justa, visando à melhoria da qualidade de vida da sociedade. É um processo de mudança social de longo prazo, dinâmico, contínuo e sem uma trajetória pré-determinada ou completamente previsível, embora muitas etapas possam ser planejadas e resultantes das ações deliberados dos vários atores e instituições presentes no território.

Embora sem se referir ao território e não pretendendo apresentar uma solução, Polanyi (2000) fornece algumas pistas para se tentar compreender a origem de alguns gargalos ou ausência de explicações para o funcionamento da atual economia de mercado, e do pensamento econômico dominante, que tenta criar uma "sociedade de mercado". Esse autor fornece uma estrutura teórica que pode contribuir para explicar as relações da economia de mercado com a sociedade e as formas de construção social dos mercados contemporâneos, demonstrando que até o final do século XVIII, em todas as sociedades, o sistema econômico estava imerso no sistema social. Dessa forma, nenhuma economia era controlada por mercados, embora esses estivessem presentes na história da humanidade, mas apenas como um aspecto acessório da estrutura institucional controlada e regulada pela sociedade e reduzindo a abrangência da economia (POLANYI, 2000).

Na sua visão de uma economia de mercado imersa na sociedade, Polanyi (2000) fugiu da concepção reducionista-cartesiana do homo economicus e se recusou a aceitar o determinismo matemático na economia. Sua tese reaproxima economia, antropologia, história, geografia e outras ciências sociais por meio de instrumentos analíticos multidisciplinares da Sociologia Econômica, da Economia Regional, Industrial, Política e Institucional e da Geografia Econômica. 
A "imersão" (embeddedness) da economia de mercado na sociedade e o "duplo movimento" das dinâmicas socioeconômicas

De acordo com Polanyi (2000), os sistemas econômicos na Europa, a partir da metade do século XIX, estavam separados institucionalmente do resto da sociedade. Em vez de a economia estar imersa nas relações sociais, eram essas que estavam imersas nos sistemas econômicos. O processo de transformação e de democratização dos países capitalistas europeus iniciou na segunda metade do século XIX e encerrou na metade do século XX, com a derrocada do estado liberal e com o fim do padrão-ouro e do mercado autorregulável. Esse processo, caracterizado pelo apogeu e colapso da "civilização liberal" do século XIX, foi descrito por Karl Polanyi na sua obra A Grande Transformação, publicada pela primeira vez em 1944. Segundo ele, a "'civilização liberal" do século XIX atingiu o seu auge nos primeiros anos do século passado e entrou em crise nos anos 30, quando foram destruídos os seus quatro pilares: o "equilíbrio de poder", o "sistema monetário internacional", baseado no padrão-ouro, os "Estados e crenças liberais" e os "mercados autorregulados" (POLANYI, 2000). A tese de Polanyi inaugura a nova economia política internacional e a nova sociologia econômica quando define outro ponto de partida para o debate sobre as relações entre Estado, sociedade e a riqueza capitalista.

Ao propor o conceito de "imersão" ou "enraizamento" (embeddedness) social dos mercados, Polanyi (2000) afirma que sempre foi impossível separar mentalmente a economia de outras atividades sociais, quando as sociedades garantiam os meios materiais para a satisfação das suas necessidades através da reciprocidade e da redistribuição. $A$ ideia de uma economia de mercado inserida no sistema social considera as relações econômicas como partes componentes das relações sociais. Dessa forma, a reciprocidade aparece como um importante mecanismo potencial de funcionamento das economias contemporâneas. Consequentemente, os dois mecanismos de funcionamento dos sistemas locais de produção são os mercados, necessários para a regulação da demanda e da oferta de bens e serviços, e a reciprocidade, que, grosso modo, consiste em uma troca de bens e serviços gratuitos e que vai além de uma transação puramente comercial.

Esse autor sugere a existência simultânea, no interior do sistema capitalista, de um contraditório "duplo movimento", por um lado uma tentativa de estabelecer um mercado autorregulado e, por outro, a pressão pela proteção social, que inclui a preservação do homem e da natureza e a organização produtiva. Esse "duplo movimento" contraditório seria reflexo, por um lado, de uma expansão dos mercados e, por outro, de um movimento simultâneo de autoproteção da sociedade. O "duplo movimento" expressa também, por um lado, o princípio liberal de um mundo sem fronteiras (globalização) e sem poderes políticos e, por outro, o princípio da territorialidade, que vê o fortalecimento do poder do Estado e da organização social para manter a paz.

Polanyi (2000) constatou que o processo de desenvolvimento do capitalismo era consequência de um "duplo movimento", dois princípios que agem em sentidos opostos e que convivem de forma permanente e contraditória dentro do capitalismo, o "princípio do liberalismo" com o objetivo de "estabelecer um mercado autorregulável" e o "princípio da autoproteção social" com a finalidade de "preservar o homem e a natureza, além da organização produtiva" (p. 164). O primeiro é determinado pela economia 
de mercado, que converte o trabalho humano, a natureza e o dinheiro em mercadoria e a sociedade em uma sociedade de mercado, e que atualmente se verifica pelo processo de globalização econômico-financeira. O segundo é o contramovimento socioambiental de comportamento defensivo de uma sociedade que enfrenta mudanças, que ocorre em nível local-regional, que pode se manifestar através de várias formas de democratização política e social e da construção de redes de proteção coletiva da população e que se propõe a "enfrentar a ação do mercado em relação aos fatores de produção - trabalho e terra" (POLANYI, 2000, p. 162).

Com relação ao mercado, seria de se esperar que as trocas mercantis locais evoluíssem, aos poucos, para o âmbito nacional ou internacional, no entanto foi a intervenção do Estado e a expansão do comércio exterior que, progressivamente, "penetraram" nos mercados locais e os "modernizaram", criando uma economia de mercado autorregulável. Organizar a economia a partir do mercado pressupõe a transformação da natureza, do homem e do dinheiro em mercadorias, passando os dois primeiros a serem denominados pela teoria econômica, respectivamente, de "terra" e "trabalho". E ainda, como consequência do surgimento e desenvolvimento da indústria, passou-se a exigir que a terra, o trabalho e o dinheiro fossem transformados em mercadoria, uma vez que são elementos essenciais e devem estar disponíveis para a indústria. A revolução industrial surgiu juntamente com a ideia de um mercado autorregulável e a consequência da introdução do sistema industrial foi a ampliação do mecanismo de mercado aos componentes da indústria - trabalho, terra e dinheiro. Esses são definidos por Polanyi (2000) como mercadorias fictícias, pois não foram produzidos como mercadorias, mas são tratadas como se fossem. A crítica de Polanyi ao industrialismo se configura no que ele entende como a "máquina que criou uma nova civilização". Já a revolução industrial se tornou num dos grandes momentos da história do homem, no entanto alterou nossa relação com a natureza.

Como resposta à crítica de que isso poderia levar a uma limitação da liberdade total, Polanyi (2000) entende que ter liberdade em uma sociedade complexa implica aceitar a realidade da existência da sociedade e a impossibilidade de se viver em tal sociedade sem nenhum compromisso mútuo e/ou de cooperação. Para isso, é necessário algum grau de regulação e controle, uma vez que, em qualquer sociedade, em diferentes graus, existem relações conflitosas de poder e a "compulsão", as quais se resolvem somente por meio da regulação social sobre o mercado. As pressões da sociedade pelo estabelecimento de controles sociais sobre os mercados podem ser listados como contramovimentos socioambientais que levam ao crescimento da importância dada à questão ambiental, mudam a forma como os recursos naturais são hoje mensurados no mercado, tentam superar a condição de mercadoria do trabalho, quando o tempo de trabalho deixa de ser a medida do trabalho, lutam contra a especulação financeira internacional, criam redes de comércio justo e de economia solidária na tentativa de tirar o dinheiro da condição de mercadoria.

Enfim, a imersão da economia de mercado no sistema social significa, basicamente, reconhecer a inviabilidade de transformar terra, pessoas e dinheiro em mercadoria, a possibilidade de reintroduzir a dimensão ética e moral na reflexão econômica, redescobrir a importância das instituições, comunidades, política e cultura sobre a economia. 
Além dessas destacadas características da imersão social da economia, ainda é importante salientar que essa situação favorece a diversificação do território e a integração deste com o "local", destaca o papel das economias não-monetárias e da reciprocidade. Por fim, Polanyi (2000) chama a atenção para os graves riscos do mercado "autorregulável" sobre a coesão social e, até mesmo, para as possíveis consequências negativas de um industrialismo "extremista" sobre a sociedade e a natureza.

A reciprocidade aparece como um importante mecanismo de funcionamento das economias contemporâneas. Assim, dois mecanismos de funcionamento dos sistemas produtivos, que se formam e/ou se desenvolvem nos territórios e que passam a serem os principais responsáveis pelo "duplo movimento", são os mercados e a reciprocidade. Enquanto o primeiro consiste numa relação de compra e venda regulada unicamente pelo sistema de preços, o segundo é uma troca de bens e serviços gratuitos e que vai além de uma transação puramente comercial. As relações de reciprocidade estão presentes, por exemplo, na família, entre amigos ou em algumas relações comunitárias ou sociais. Elas são resultantes de sentimentos reconhecidamente ligados a outras relações mais complexas, tais como as de fidelidade, de gratidão e de identidade. No Brasil, verifica-se que essas relações, que eram essenciais para a sobrevivência familiar e da população no início imigração e da ocupação dos territórios, embora ainda subsistam em alguns territórios rurais, tenderam a se perder ao longo do processo histórico de desenvolvimento econômico do país. Essa perda ocorre na medida em que aumenta a integração da economia dos territórios aos mercados e processos econômicos nacionais e globais.

A situação, neste início do século XXI, é como se o mundo tivesse finalizando uma nova e breve "civilização liberal", iniciada com a crise fordista da década de 1970, que agora também estaria entrando em crise. Atualmente, um processo semelhante à "grande transformação" parece querer se repetir, quando se verifica o início de um período de mudanças no capitalismo contemporâneo, onde as críticas às políticas liberais do Consenso de Washington são generalizadas. Além disso, o poder das armas está presente em várias partes do globo, e a economia mundial experimenta uma crise financeira sem precedentes, os quais ameaçam o crescimento produtivo e do atual modelo capitalista. Em grande parte dos países da periferia capitalista mundial, incluindo o Brasil, vive-se um momento em que ocorre um processo de transformação e democratização da sociedade, muito semelhante, embora com suas etapas muito mais reduzidas em termos de tempo, ao que ocorreu durante aproximadamente um século nos países capitalistas europeus.

Por fim, na economia industrial e na economia regional, algumas questões ainda permanecem sem respostas, tanto em relação à organização espacial das empresas frente à globalização dos mercados, como em relação à localização e utilização de recursos ambientais e tecnológicos. Assim, o território, como um novo ator do desenvolvimento socioeconômico, emerge como um importante objeto de análise, com potencial para responder por algumas dessas questões, pois carregam consigo uma história e formas institucionais particulares. Além disso, têm objetivos diferentes daqueles das empresas, embora sejam interdependentes com os objetivos destas. Consequentemente, a formulação de políticas socioeconômicas territoriais adequadas passa por uma delicada articulação entre empresas e territórios. Além disso, pela primeira vez na história do capitalismo, está sendo possível combinar trabalho de alto nível tecnológico com a di- 
versificação de produtos e processos, ao mesmo tempo em que o sistema produtivo se modifica e faz surgir "um mosaico de territórios diferenciados" (BENKO, 2002).

\section{Considerações finais}

Neste artigo, buscou-se apresentar algumas interpretações teóricas que fazem parte do debate sobre os reflexos da reestruturação do sistema produtivo fordista-industrial e do atual contexto de crise do capitalismo mundial, que "estourou" em 2008, mas que, aparentemente, vinha sendo gerada já há algum tempo dentro do sistema financeiro. De maneira geral, acredita-se que as causas que deram origem à crise mundial do fordismo são tanto internas, como a crise do próprio modelo de desenvolvimento, quanto externas, como a internacionalização da economia.

A "Teoria da Regulação" explica a instabilidade do sistema capitalista por meio da divisão do capitalismo em períodos específicos de estabilidade socioeconômica seguidos de períodos de crise. Os regulacionistas argumentam que a contradição inerente ao sistema capitalista não permite que se tenham períodos contínuos de estabilidade e crescimento, gerando crises e a necessidade de uma reestruturação e de um novo mecanismo de estabilidade. Para esses, no atual modelo de desenvolvimento fordista, vem acontecendo uma crise de eficácia e uma falta de legitimação do modelo, resultante da falta de flexibilidade e sustentabilidade das cadeias de produção de bens e serviços e da ineficiência das atuais políticas macroeconômicas para garantir a acumulação capitalista. Em consequência, então, o que se verifica hoje é uma estratégia de "saída" do fordismo, a partir da flexibilização das relações de trabalho e de um aprofundamento das relações capitalistas. Outras vertentes teóricas que interpretam as mudanças do capitalismo contemporâneo são os "neoschumpeterianos" e os "neofordistas".

No entanto, com relação aos efeitos da reestruturação produtiva mundial sobre o desenvolvimento local, as ideias que sustentam o debate acadêmico ainda são as da "globalização" e das diversas interpretações de desenvolvimento local, endógeno e/ou territorial, um leque com diferentes graus de acesso aos mercados externos.

No texto, argumentou-se em prol de uma perspectiva territorial representativa da articulação de perspectivas territoriais e institucionais do desenvolvimento, segundo a qual os efeitos do capitalismo global sobre as dinâmicas locais de desenvolvimento podem ser mediados por estruturas de regulação e governação. Assim podem ser explicadas a formação e a manutenção de diversificadas dinâmicas socioeconômicas de desenvolvimento, que aproveitam as potencialidades locais dos territórios e, ao mesmo tempo, as oportunidades externas. Essas articulações e a identificação das relações entre o global e o local dentro do território e as ligações entre esses referenciais foram realizadas com base nos pressupostos teóricos que sustentam a "imersão" ou "enraizamento" (embeddedness) da economia de mercado no sistema social. Esses são os principais subsídios teóricos de sustentação de uma abordagem para o estudo do desenvolvimento socioeconômico dos territórios.

Como resposta à questão de como a organização e a participação dos atores e o dinamismo das instituições pode contribuir para o desenvolvimento e para a competitividade 
de um território, foram feitas algumas considerações teóricas. Inicialmente, afirmou-se que as diferentes dinâmicas de cooperação entre os atores socioeconômicos e políticos locais são determinantes das dinâmicas e dos processos de desenvolvimento territorial. Além disso, a força da dinâmica socioeconômica do desenvolvimento territorial é diretamente proporcional à qualidade das suas estruturas internas e na ação dos seus diversos atores no aproveitamento do seu potencial endógeno, incluindo a ação do Estado nessas dinâmicas de desenvolvimento territorial. Os fatores internos com influência direta sobre essas dinâmicas podem ser potencializados pela capacidade organizativa, técnica e gerencial das administrações locais, pela capacidade de articulação e mobilização dos recursos, assim como pela formação social e de uma base econômica local. Por essa razão, para promover o desenvolvimento de um determinado território, independentemente da sua escala, é necessário estudar o grau e a forma de aproveitamento dos seus recursos e de suas potencialidades endógenas e os elementos determinantes das diferentes dinâmicas estruturais e institucionais desses processos.

Em síntese, as oportunidades locais de desenvolvimento territorial dependem das especificidades e da dinâmica de cada território. Essas refletem a complexidade de combinações de variáveis socioeconômicas e ambientais endógenas e dessas com variáveis exógenas ou globais, assim como das formas de regulação e de governação estabelecidas entre os diferentes atores sociais, empresariais e do Estado, com atuação local-territorial.

\section{Referências}

BECKER, Bertha. O Uso Político do Território: questões a partir de uma visão do terceiro mundo. In: BECKER, Bertha; COSTA, Rogério; SILVEIRA, Carmem (Orgs.). Abordagens Políticas da Espacialidade. Rio de Janeiro: UFRJ, 1986. p. 1-8.

BENKO, Georges. Economia, Espaço e Globalização: na aurora do século XXI. São Paulo: Hucitec-Annablume, 2002.

BENKO, G.; LIPIETZ, A. O Novo Debate Regional. In: BENKO, G.; LIPIETZ, A. (Orgs.). As Regiões Ganhadoras-Distritos e Redes: os novos paradigmas da geografia econômica. Oeiras: Celta, 1994.

BOYER, Robert. As alternativas ao Fordismo. Oeiras: Celta, 1994.

Une Théorie du Capitalisme est-elle Possible? Comissão Europeia (1999), Schéma de Développement de l'Éspace Communautaire: Vers un développement spatial équilibré et durable du territoire de l'Union européenne. Paris: Odile Jacob, 2004.

BOYER, R.; SAILLARD, Y. (Eds.). Théorie de la Régulation - L'État des Savoirs, Paris: La Découverte. 1995.

FIORI, José Luiz. Globalização Econômica e Descentralização política: um primeiro balanço. Ensaios FEE, Porto Alegre, v. 15, n. 2, p. 295-311, 1994.

HELD, D.; Mc GREW, A. Prós e Contras da Globalização. Rio de Janeiro: Jorge Zahar, 2001. 
LIPIETZ, Alain. As relações Capital-trabalho no Limiar do século XXI. Ensaios FEE, Porto Alegre, ano 12, n. 1, 1991.

MORAES, Jorge Luiz Amaral de. Dinâmicas Sócio-Econômicas de Desenvolvimento dos Territórios Rurais: Os Sistemas Produtivos Localizados (SPLS) da Região Vale do Rio Pardo - RS. 2008. Tese (PGDR) - Universidade Federal do Rio Grande do Sul, Porto Alegre, 2008. Disponível em: <http://hdl.handle.net/10183/15636>.

PECQUEUR, Bernard. Le développement territorial: une nouvelle approche des processus de développement pour lês économies du Sud. Institut de Géographie Alpine. Grenoble: Université Joseph Fourier, 2004.

POLANYI, Karl. A Grande Transformação: as origens da nossa época. 8. ed. Rio de Janeiro: Campus, 2000.

RAFFESTIN, Claude. Por uma Geografia do Poder. São Paulo: Ática, 1993.

REIS, José. O Institucionalismo Económico: Crónica sobre os saberes da economia. Notas Econômicas. Revista da Faculdade de Economia da Universidade de Coimbra, n. 11, p. 130-149. 1998.

Os Espaços da Indústria: a regulação econômica e o desenvolvimento local em Portugal. Porto: Afrontamento, 1992.

Uma Epistemologia do Território. Lisboa: Instituto Superior de Economia e Gestão (ISEG), Universidade Técnica de Lisboa, 2006.

SCHNEIDER, S.; TARTARUGA, I. G. P. Do Território Geográfico à Abordagem Territorial do Desenvolvimento Rural. Jornadas de Intercambio y Discusión: El Desarrollo Rural en su Perspectiva Institucional y Territorial. 2005. Flacso Universidad de Buenos Aires/ Conicet, 2005.

VÁZQUEZ-BARQUERO, Antonio. Desenvolvimento Endógeno em Tempos de Globalização. Porto Alegre: FEE/UFRGS, 2001. 